\title{
Modelo de Análise de Erros aplicado à produção escrita de surdos: \\ o estudo das preposições no português como Segunda Língua
}

\author{
Patricia ASPILICUETA
}

Universidade Estadual do Centro-Oeste

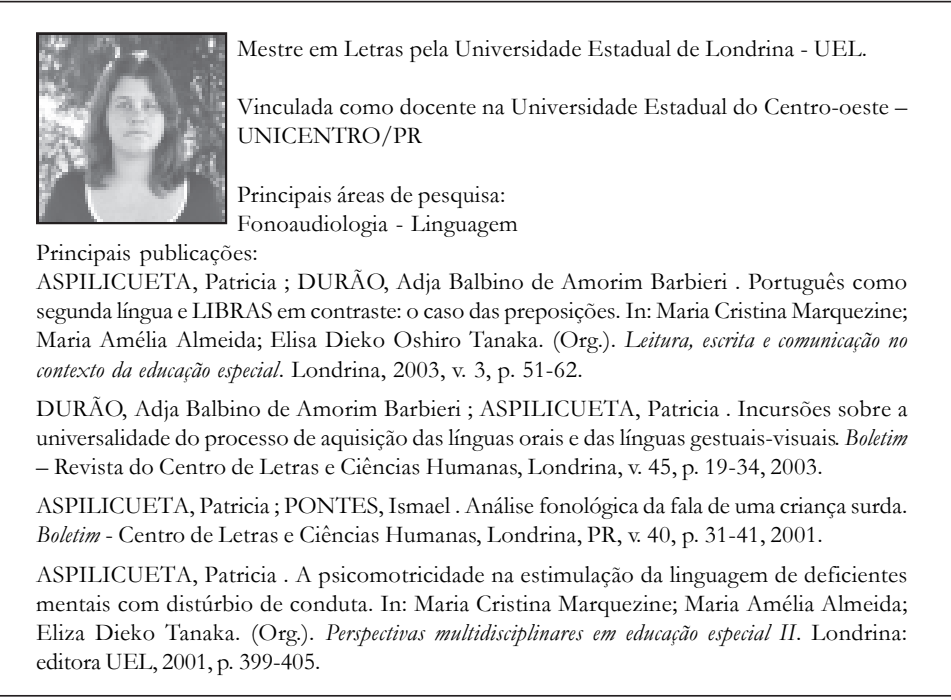

SIGNUm: Estud. Ling., Londrina, n. 9/1, p. 11-42, jun. 2006 
Resumo: Na ótica do Bilingüismo, encara-se a Língua Brasileira de Sinais como a primeira língua do surdo e o português como sua segunda língua, aproximando os estudos sobre aquisição da língua portuguesa pelo surdo dos trabalhos voltados para o ensinoaprendizagem de segundas línguas. Partindo-se desse referencial teórico, investigou-se a produção escrita de 20 alunos surdos bilíngües de 5. a a 8. a série do Instituto Londrinense de Educação de Surdos, descrevendo como esses sujeitos lidam com as preposições na língua portuguesa. Para tal, recorreu-se ao Modelo de Análise de Erros a fim de identificar, classificar e explicar os erros relacionados às preposições que os aprendizes surdos produziram ao elaborar textos escritos em português. Nos resultados encontrados, identificou-se a omissão das preposições a, até, com, de, em, para, por e sobre a qual demonstrou tendência à fossilização. A presente pesquisa contribui para a sedimentação de novos paradigmas educacionais e para a busca de caminhos metodológicos efetivos para o ensino de português como segunda língua do surdo.

Palavras-chave: Análise de Erros, escrita, surdo

Abstract: According to Bilingualism, the Brazilian Sign Language is seen as the first language for the deaf, and Portuguese as their second language, getting the studies on the acquisition of Portuguese by the deaf closer to the work related to second language teaching and learning. Based on such theoretical reference, the written production of 20 bilingual deaf students was investigated, students attending from $5^{\text {th }}$ to $8^{\text {th }}$ grade at Instituto Londrinense de Educação de Surdos (Londrina Institute of Education for the Deaf), describing how these subjects deal with prepositions in the Portuguese Language. For such, the Error Analysis Model was used in order to identify, classify, and explain the errors related to the prepositions that the deaf learners produced in making written texts in Portuguese. In the results, the omission of prepositions $a$ (to), até (until), com (with), de (of, from), em (in, on, at), para (to, for), por (by, for), and sobre (about, on), they showed a tendency to fossilization. The present research contributes to the sedimentation of new educational paradigms and to the search for effective methodological ways in the teaching of Portuguese as a second language for the deaf.

Key words: Error Analysis, written production, deaf 
Resumen: En la óptica del Bilingüismo, se ve a la Lengua Brasileña de Señales como la primera lengua del sordo y el portugués como su segunda lengua, acercando los estudios sobre adquisición de la lengua portuguesa por parte del sordo de los trabajos que se centran en la enseñanza-aprendizaje de segundas lenguas. Partiéndose de ese referencial teórico, se investigó la producción escrita de 20 estudiantes sordos bilingües de $5^{\mathrm{a}}$. a $8^{\mathrm{a}}$. Cursos del Instituto Londrinense de Educação de Surdos, describiendo como esos sujetos utilizan las preposiciones de la lengua portuguesa. Para ello, se utilizó el Modelo de Análisis de Errores, tratando de identificar, clasificar y explicar los errores relacionados con las preposiciones que los aprendices sordos produjeron al elaborar textos escritos en portugués. En los resultados encontrados, se identificó la omisión de las preposiciones a, até, com, de, em, para, por e sobre, la cual demostró tendencia a fosilizar. La presente investigación contribuye para la sedimentación de nuevos paradigmas educacionales y para la busca de caminos metodológicos efectivos para la enseñanza de portugués como segunda lengua del sordo.

Palabras-clave: Análisis de Errores, escrita, sordo

\section{Introdução}

As discussões atuais sobre a linguagem de indivíduos surdos apontam para o bilingüismo como uma alternativa educacional que viabiliza o seu desenvolvimento lingüístico, cognitivo e social. Skliar (1997) ressalta que o termo bilingüismo reflete um conceito que extrapola a dimensão lingüística, devendo ser entendido como uma abordagem educacional permeada por elementos antropológicos, políticos, culturais e pedagógicos. Goldfeld (1998) e Triadó (1999) definem o bilingüismo como o uso alternado de duas línguas por um indivíduo ou por um grupo social, no caso dos surdos brasileiros, o domínio da Língua Brasileira de Sinais (LIBRAS) e do português. 
Nessa perspectiva, considera-se a língua de sinais como a língua materna (LM) ou a primeira língua (L1) do surdo e a língua nacional como a sua segunda língua (L2). Esse ponto de vista é defendido por diversos autores (SACKS, 1990; QUADROS, 1997; SKLIAR, 1998; JOKINEN, 1999; ALMEIDA, 2000).

Abordar a linguagem do surdo do ponto de vista de uma comunidade bilíngüe desloca a questão da surdez do discurso médico e patologizante, inserindo-a em uma discussão mais ampla sobre a diferença lingüística e suas implicações sócio-culturais.

Dentro dessa ótica, Fernandes (1999) aponta que os erros cometidos por alunos surdos na produção escrita do português não são desvios da normalidade, mas sim construções peculiares que constituem sua interlíngua, decorrentes da aprendizagem de uma L2. O processo de apropriação de uma L2 permeia-se pela interferência das estruturas da L1 na aprendizagem da L2. Erros são cometidos a partir da formulação de hipóteses que se baseiam nas regras da L1 ou na generalização das regras já aprendidas da L2. Essa perspectiva fundamenta-se nos pressupostos de Corder (1967) que vê o erro como evidência do sistema lingǘstico que o aprendiz utiliza naquele dado momento e ressalta que o erro tem importância fundamental para o aprendiz, pois lhe permite testar suas hipóteses sobre a L2, que é a língua alvo, progredindo em sua aprendizagem.

Os trabalhos que se preocuparam em pesquisar as principais características da produção de textos escritos por indivíduos surdos (RABELO \& SOUZA, 1998; FERNANDES, 1999; MARCONDES \& COSTA, 2000) apontam as seguintes singularidades na escrita do surdo: verbos com tendência a serem apresentados no infinitivo; flexão de tempo através de itens lexicais isolados ou verbos 
flexionados inadequadamente; ausência de verbos auxiliares e de ligação; omissão ou utilização inadequada de artigos e conectivos; concordância nominal e verbal inadequada; dificuldades com o léxico, limitado ou inadequado; dificuldades na seleção e na ordenação dos elementos gramaticais na frase comprometendo a coerência do texto.

A ausência, ou o pouco uso das preposições, é constantemente citada nas pesquisas que analisam a escrita de surdos (FERNANDES, ibid.; PEREIRA, 1999; ALMEIDA, 2000). O interesse da presente pesquisa no estudo das preposições recai sobre o fato de ser essa classe de palavras considerada inexistente em LIBRAS. Valverde (1990) e Almeida (ibid.) afirmam que os artigos, as preposições e as conjunções são inexistentes em LIBRAS e justificam essa inexistência por estarem tais elementos contidos dentro do sinal.

Coutinho (2000, p.130) corrobora essa idéia, todavia, reporta que existem alguns sinais para representar conectivos:

Observamos que pelo fato de nós, ouvintes, precisarmos destas palavras num processo de comunicação e por não compreendermos a estrutura da LIBRAS, foram criados alguns sinais para: e, para, com, entre, etc. Poucos são os surdos que os incorporam em seu discurso. Isto pode acontecer quando os mesmos têm algum domínio da estrutura da Língua Portuguesa ou absorvem estes sinais dos ouvintes.

Baseada nesses pressupostos, a presente pesquisa visa investigar os erros relativos ao uso das preposições na produção escrita de aprendizes surdos de português, demonstrando que há interferência da LIBRAS (L1) na aprendizagem da língua portuguesa (L2). 
As duas línguas envolvidas na questão bilíngüe do surdo apresentam diferenças marcantes, derivadas principalmente do fato de expressarem distintas modalidades de língua, uma viso-espacial e a outra auditivooral. Essa diferença entre a LIBRAS e o português favorece a interferência, o que vai ao encontro do objetivo do estudo de demonstrar a ocorrência de interferência da LIBRAS no processo de apropriação do português escrito pelo surdo, gerando erro interlingual.

O estudo avança a fim de verificar se há alguma evolução na apropriação do uso de preposições no decorrer do processo educacional de $5 .^{a}$ a $8 .^{a}$ séries ou se o erro se fossiliza.

\section{Modelo de Análise de Erros e o papel do fenômeno de transferência de primeira língua na aprendizagem de segunda língua}

Uma das características que diferenciam a aquisição de L2 da aquisição de L1 diz respeito à transferência lingüística. Por transferência lingüística entende-se o papel que a L1 desempenha no processo de aquisição de uma L2. Para Schachter (1988), o aprendiz vai transferir algumas estruturas da língua materna para a língua alvo, podendo facilitar ou inibir o processo de apropriação da L2.

A noção de transferência surgiu atrelada ao Modelo de Análise Contrastiva (AC). A preocupação central da $\mathrm{AC}$ consistia na previsão das áreas mais propensas à geração de erros no processo de aprendizagem de uma L2 por um falante de determinada L1. Para tal, a AC utiliza como procedimento o contraste das línguas envolvidas nesse processo de aprendizagem, identificando as áreas que contêm semelhanças ou diferenças significativas. 
Resulta do trabalho de Lado (1963) a disseminação do conceito de transferência como fator fundamental na aprendizagem de L2. Para o autor, as áreas em que há semelhanças ou diferenças entre a L1 e a L2 mostram-se favoráveis à transferência positiva ou negativa, respectivamente, e quanto mais significativas as diferenças entre as duas línguas maiores as dificuldades para sua aprendizagem.

Até os anos 70, presumia-se que a transferência fosse a maior responsável pelas dificuldades encontradas pelos aprendizes de uma L2. Nickel (1989) e Ellis (1990), discutindo as controvérsias em relação à importância do papel da transferência na aquisição de uma L2, relatam que, com o avanço das pesquisas, constatou-se que uma grande quantidade de erros cometidos pelos aprendizes de L2 não podiam ser explicados com base na transferência lingüística e a interferência perdeu seu lugar de destaque como fonte principal das dificuldades na aquisição de uma L2. Passouse a considerar que os erros cometidos por aprendizes de uma L2 relacionam-se, principalmente, com a construção gradual de um sistema de regras da própria L2, semelhantes aos erros das crianças nativas na aquisição daquela língua como L1 ou erros de desenvolvimento (DULAY \& BURT, 1974; GHADESSY, 1989).

A idéia de previsão de erros e da interferência, como único fator gerador de erro interlingual, foi o que motivou a maioria das críticas formuladas a respeito da AC. No entanto, esse conceito reatualizou-se a partir de estudos fundamentados no Modelo de Análise de Erros (AE) e de interlíngua, que apontaram outros fatores que poderiam induzir ao erro, sendo a interferência analisada atualmente como um dos fenômenos causadores de erros no processo de aquisição de L2. 
Autores como Nickel (1989), Lennon (1991), Abbas (1995) e Durão (1999) relatam o surgimento do Modelo de AE, a partir das críticas feitas à AC. A principal diferença entre os dois modelos situa-se exatamente sobre o foco da AE que recai sobre erros efetivamente produzidos, surgidos em um corpus real e não hipotetizados a partir do contraste entre as línguas.

Ao propor a metodologia do Modelo de AE, Corder (1967) contribui para os estudos de aquisição de L2 com uma visão nova do significado e importância do erro. Nesta perspectiva, o erro tem importância fundamental para o aprendiz, pois lhe permite testar suas hipóteses sobre a língua alvo, progredindo em sua aprendizagem.

O conhecimento que o aprendiz possui sobre a língua alvo em um dado momento, Corder (ibid.) denominou de competência transitória. O termo ressalta o caráter passageiro dessa competência, pois o aprendiz segue adquirindo novos conhecimentos sobre a língua alvo e, portanto, modificando sua competência num momento posterior, passando de um estado a outro. Selinker (1972) propõe o termo interlíngua para referir-se à produção do aprendiz ao expressar-se na língua alvo, utilizando, para isto, características das duas línguas envolvidas: a língua materna e a língua alvo.

O interesse do Modelo de AE recai sobre a descrição da interlíngua. Corder (ibid.) apresenta uma metodologia para essa descrição, propondo três etapas para a AE: 1. identificação das orações idiossincrásicas e formulação de uma oração correspondente na língua alvo; 2. comparação das duas orações; 3. explicação das orações idiossincrásicas com fins teóricos e pedagógicos. Esses passos foram ampliados para cinco em Corder apud Lennon (1991) acrescentando: 4.explicação das causas psicolingüísticas 
dos erros; 5.avaliação da gravidade dos erros, esquematizando-se um ranking de gravidade.

O erro pode fixar-se na interlíngua, tratando-se, neste caso, de um erro fossilizado. Durão (2000, p.47) define o fenômeno da fossilização como “... reaparecimento regular de estruturas lingüísticas que não se correspondem às da língua objeto produzidas por aprendizes de L2 e que se fixam na interlíngua dos estudantes".

Selinker (1972) atribui a fossilização à transferência lingüística, transferência de instrução, estratégias de aprendizagem, estratégias de comunicação e hipergeneralização. Mukattash (1986) indica uma provável relação entre transferência de L1 e fossilização, observando em seu estudo sobre erros fossilizados que a interferência provou ser geradora de grande quantidade desse tipo de erro. Nakuma (1998), ao revisar os estudos sobre fossilização, aponta esta mesma relação como, implícita ou explicitamente, presente nas concepções sobre o tema.

\section{Método}

O Modelo de AE foi aplicado, no presente estudo, à produção escrita de aprendizes surdos de português. Este modelo serviu de método para investigar a produção escrita de aprendizes surdos de português quanto aos erros no uso das preposições da língua portuguesa. A pesquisa configura-se como um estudo do tipo descritivo (TRIVIÑOS, 1994).

\subsection{Sujeitos e Local}

A coleta de dados foi aplicada à totalidade dos alunos de 5. a 8. ${ }^{a}$ séries de uma escola especial de surdos do Estado 
do Paraná, totalizando trinta e quatro alunos. Entretanto, para efeito de análise, fez-se necessário uniformizar a quantidade de textos por série, elaborando-se critérios para exclusão dos sujeitos excedentes em cada série, critérios esses relativos à faixa etária, a ser usuário de LIBRAS e ao número médio de palavras por texto. Restaram vinte sujeitos, sendo cinco por série, que passaram a constituir os sujeitos da pesquisa.

Os vinte sujeitos da pesquisa eram adolescentes surdos bilíngües, usuários de LIBRAS e aprendizes de português, filhos de pais ouvintes. As idades variaram entre 12 e 19 anos e a maioria dos sujeitos pertencia ao sexo masculino (65\%). Todos os sujeitos apresentavam surdez neurossensorial bilateral cujo grau variou entre profundo (acima de $91 \mathrm{~dB}$ ) e severo (entre 70 e $90 \mathrm{~dB}$ ).

\subsection{Procedimentos}

2.2.1 Contraste entre Preposições na Língua Brasileira de Sinais e na Língua Portuguesa como L2

No sentido de apontar as estruturas da L2 que proporcionariam dificuldades ou facilitação da aprendizagem, de acordo com o grau de diferença e semelhança existente entre as preposições da língua materna dos aprendizes (a LIBRAS) e a língua objeto de estudo (o português), elaborou-se um quadro contrastivo entre as preposições da LIBRAS e da língua portuguesa.

\subsubsection{Modelo de Análise de Erros}

Seguiram-se os passos elaborados por Corder, apud Lennon (1991), para o Modelo de Análise de Erros, a saber, 
seleção de um corpus lingüístico, identificação dos erros nesse corpus, classificação dos erros identificados, explicação das causas psicolingüísticas dos erros.

Procurou-se, ainda, verificar se houve evolução na apropriação das preposições no decorrer do processo educacional ou se o erro se fossilizou. Finalmente, buscouse argumentar sobre a fonte desses erros como sendo a interferência da LIBRAS (L1) na aprendizagem da língua portuguesa (L2) no caso de construções que envolvem as preposições.

\subsubsection{Seleção de um corpus lingüístico}

Para elicitação da produção escrita, propôs-se a seguinte dinâmica. Primeiramente, apresentou-se um filme que faz parte do vídeo Fantasia 2000. Trata-se de um desenho animado que traz as histórias contadas visualmente, sem o uso da linguagem oral. Optou-se pela utilização de um filme como deflagrador do tema da composição a fim de facilitar a reescritura do texto, pois, desse modo, o pesquisador pode basear-se no filme para esclarecer as dúvidas sobre o significado de construções duvidosas que se previa encontrar na produção escrita dos sujeitos. Após o filme, os alunos discutiram, em LIBRAS, sobre o que entenderam a respeito do filme. Na seqüência, solicitou-se aos alunos que escrevessem a história do filme.

\subsubsection{Identificação dos erros no corpus}

Os textos escritos pelos sujeitos da pesquisa foram digitados, numerados e reescritos pela pesquisadora, resultando na elaboração de quadros que comparam a oração do aprendiz à sua reescritura. Cabe sinalizar que, dessa forma, 
registram-se todos os casos de uso das preposições, sejam erros, acertos ou omissões.

\subsubsection{Classificação dos erros}

No presente estudo, a forma dessa classificação dos erros relativos às preposições emergiu durante a própria análise, optando-se pela adoção do critério gramatical. Os erros foram subdivididos em erros de omissão, de escolha inadequada, de adição ou de ordenação.

Os erros de omissão configuraram-se como erros pelo não uso da preposição, omitindo-se a preposição requerida para determinado contexto. Ex: "fala música \# piano" (tocava música ao piano).

Os casos de escolha inadequada da preposição foram aqueles em que o aprendiz utilizou a preposição x quando o correto seria a preposição y. Esse tipo de ocorrência foi computado em relação à preposição x, ou seja, àquela que foi efetivamente escolhida pelo aprendiz. Ex: "sonho patinação do gelo" (Sonbou com patinação no gelo).

Os erros por adição referiram-se à colocação da preposição em situações em que ela não deveria ser utilizada. Ex: "Ele pegou de onibús" (Ele pegou \# o ônibus).

Identificou-se como escolha correta da preposição os casos em que o aprendiz usou a preposição adequada naquele contexto. Entretanto, a essa escolha correta, por vezes, associou-se uma ordenação atípica dos elementos na frase, que se passou a denominar como erro de ordenação. Apesar de haver feito a escolha correta da preposição, sua colocação na frase implicou em erro. Ex: "a maça na caiu chão" (uma maça caiu no chão).

A análise de erros foi feita tanto em relação a cada série separadamente quanto se considerando a soma dos erros de 5. ${ }^{a}$ a $8 .^{a}$ série, indicando-se os erros por preposição, por tipo de erro e por texto. 


\section{Resultados}

3.1 Contraste entre preposições na Lingua Brasileira de Sinais e na lingua portuguesa como 12

A análise contrastiva das preposições nas duas línguas envolvidas, investigou as dezessete preposições essenciais do português (a, ante, após, até, com, contra, de, desde, em, para, perante, por, sem, sob, sobre, trás) e sua correspondência na LIBRAS a fim de apontar quais, dentre as preposições, apresentariam maior ou menor grau de dificuldade para aprendizagem do seu uso na língua portuguesa. Entretanto, deve-se ter em mente que já se parte de uma previsão inicial de que todas as preposições do português reservariam alto grau de dificuldade para os aprendizes surdos por ser uma classe de palavras sem grande significado para os surdos sinalizadores.

O quadro contrastivo das preposições em LIBRAS e em língua portuguesa tornou possível observar que existem preposições no português que correspondem a um único sinal em LIBRAS (com, para, trás), outras que correspondem a mais de um sinal em LIBRAS (até, contra, sem, sob, sobre) e outras que não encontram correspondência em LIBRAS (a, ante, após, de, desde, em, entre, perante, por).

A partir das idéias de Lado (1963) e da análise realizada, constatou-se que existem diferenças que afetam a forma, a distribuição e o significado das preposições em LIBRAS e em português. A forma encontra-se intrinsecamente afetada haja vista a diferença de modalidade das duas línguas. Percebeu-se, ainda, que a LIBRAS possui mais de um sinal para representar algumas preposições do português, o que se poderia entender como uma questão ligada à diferença de distribuição das preposições nas duas línguas. Outra diferença importante diz respeito ao fato de 
uma preposição em português transitar por uma gama de significados cujo sinal ou sinais correspondentes em LIBRAS não conseguem abranger por completo.

Considerando-se os fatores acima em interação, entendeu-se que as preposições com maior grau de semelhança, portanto, com menor probabilidade de gerar erro na interlíngua do surdo aprendiz de português, seriam aquelas que apresentam uma correspondência exata entre o sinal em LIBRAS e a preposição em língua portuguesa, ou seja, que usam apenas um sinal capaz de traduzir todos os significados possíveis da preposição correspondente em português. O único sinal que demonstrou tal comportamento foi o sinal de com.

Atribuiu-se um grau de diferença intermediário às preposições que conseguiram expressar todos os significados, porém utilizando mais de um sinal para tal. Enquadraram-se, nesse estágio, as preposições sem, até, contra e trás. Com um grau ainda maior de diferença nas duas línguas, consideraram-se as preposições sobre, sob e para, por deixarem uma lacuna de significados relacionados à preposição correspondente em português que não podem ser transmitidos em LIBRAS através das preposições. Finalmente, estabeleceu-se o mais alto grau de diferença para as preposições inexistentes em LIBRAS (a, ante, após, de, desde, em, entre, perante, por).

A partir do contraste entre a classe das preposições em português e em LIBRAS, perguntou-se se nos textos produzidos pelos alunos surdos seriam encontrados os erros sugeridos pela AC. No sentido de responder a tal questionamento, recorreu-se ao Modelo de AE, comprovando-se que essas previsões não se configuraram verdadeiras. 


\subsubsection{O Uso das Preposições}

O corpus compôs-se de 20 textos contendo 3.198 palavras, das quais 235 eram preposições, representando $7.3 \%$ do total de palavras. As preposições encontradas no corpus foram de, em, para, com, por, a, sobre e até. As preposições de e em foram as mais utilizadas pelos sujeitos da pesquisa, totalizando $68.1 \%$ das preposições empregadas no corpus. Acrescentando-se as ocorrências das preposições para e com, somou-se 93.2\% do total de ocorrências (Figura 1).

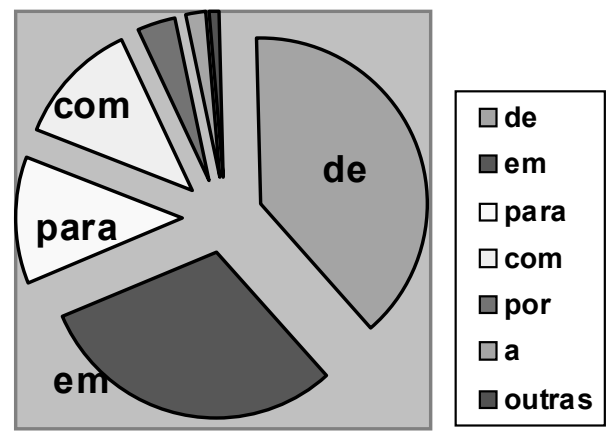

Figura 1. Produção de preposições de 5. a 8. ${ }^{a}$ série

A distribuição desse uso por série (Tabela 1) demonstra que as preposições de e em encontraram-se dentre as de uso mais freqüente em todas as séries. Entretanto, as preposições para e com iniciaram com uma freqüência de ocorrência baixa na $5 .^{a}$ série, $5.9 \%$ e $2.9 \%$ respectivamente. $\mathrm{Na} 6{ }^{a}$ série, observou-se o incremento da preposição para com $20.4 \%$, permanecendo o com em torno de $2 \%$ de freqüência. Já na $7 .^{a}$ série, constatou-se que foi a preposição com que emergiu apresentando 13.9\% 
do total das ocorrências, enquanto o para ficou restrito a 6.5\%. Ao chegar-se a $8 .^{a}$ série, houve um equilíbrio entre o uso das quatro preposições mais freqüentes.

Tabela 1. Produção de preposições por série

\begin{tabular}{cccccc}
\hline $\begin{array}{c}\text { PREPOSIÇÃO } \\
\text { a }\end{array}$ & . $^{\mathbf{a}}$ série & $\mathbf{6 .}^{\mathbf{a}}$ série & $\mathbf{7 .}^{\mathbf{a}}$ série & $\mathbf{8 .}^{\mathbf{a}}$ série & TOTAL \\
\hline até & & 1 & 4 & & 5 \\
\hline com & 1 & 1 & 15 & 12 & 29 \\
\hline de & 19 & 21 & 38 & 12 & 90 \\
\hline em & 10 & 10 & 41 & 9 & 70 \\
\hline para & 2 & 10 & 7 & 11 & 30 \\
\hline por & 2 & 4 & 3 & & 9 \\
\hline sobre & & 1 & & & 1 \\
\hline TOTAL & $\mathbf{3 4}$ & $\mathbf{4 9}$ & $\mathbf{1 0 8}$ & $\mathbf{4 4}$ & $\mathbf{2 3 5}$ \\
\hline
\end{tabular}

Ao correlacionar-se a ocorrência das preposições por série à sua distribuição pelos textos produzidos, tornouse possível aprofundar alguns pontos da análise. $O$ aparente equilíbrio no uso das preposições com, de, em e para na $8 .^{a}$ série foi apenas quantitativo, pois, considerando a abrangência da distribuição pelos textos da $8{ }^{a}$ série, constatou-se que somente as preposições de e em mantiveram-se como as de distribuição mais ampla. Confirmou-se que as preposições de e em, além de serem as de uso mais freqüente em termos quantitativos, foram as usadas por mais sujeitos em seus textos.

\subsubsection{Os Erros de Uso}

A partir de agora, passa-se a focalizar diretamente o objeto de estudo dessa pesquisa, os erros cometidos pelos aprendizes surdos ao usarem as preposições nos textos. Das 235 preposições usadas pelos sujeitos, consideraram-se 127 
casos de emprego da preposição como corretos e 108 casos como incorretos, indicando $46 \%$ de erro no uso das preposições. A tabela abaixo (Tabela 2) apresenta os números absolutos de erros e acertos para cada uma das preposições produzidas no corpus.

Tabela 2. Uso das preposições de 5 . $^{\mathrm{a}}$ a 8 . $^{\mathrm{a}}$ série

\begin{tabular}{c|c|c|c}
\hline Preposição & Acerto & Erro & Ocorrências \\
\hline $\mathrm{a}$ & 4 & 1 & $\mathbf{5}$ \\
\hline até & 1 & 0 & $\mathbf{1}$ \\
\hline com & 9 & 20 & $\mathbf{2 9}$ \\
\hline $\mathrm{de}$ & 52 & 38 & $\mathbf{9 0}$ \\
\hline $\mathrm{em}$ & 29 & 41 & $\mathbf{7 0}$ \\
\hline para & 23 & 7 & $\mathbf{3 0}$ \\
\hline por & 8 & 1 & $\mathbf{9}$ \\
\hline sobre & 1 & 0 & $\mathbf{1}$ \\
\hline TOTAL & $\mathbf{1 2 7}$ & $\mathbf{1 0 8}$ & $\mathbf{2 3 5}$ \\
\hline
\end{tabular}

Dentre as preposições que representaram maior quantidade absoluta de erros, encontraram-se as preposições em, de e com, que juntas somaram 99 erros, correspondendo a $91.7 \%$ do total de erros de uso. A preposição para, com 7 erros, representou $6.5 \%$ dos erros de uso identificados na produção escrita dos alunos surdos. Não se constatou erro quanto ao uso das preposições até e sobre e apenas uma ocorrência de erro no uso das preposições a e por (ver Figura 2). 


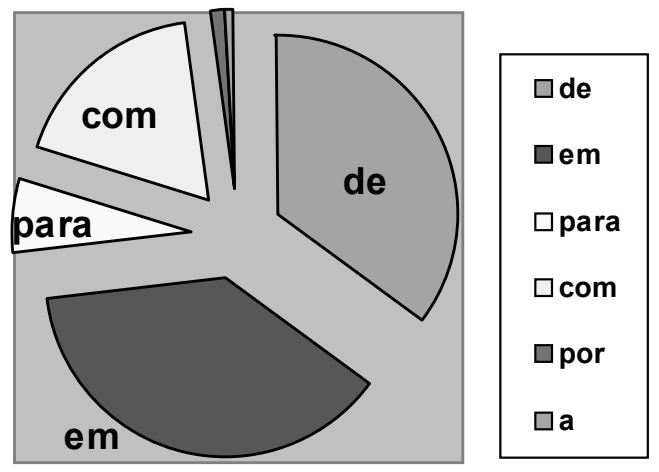

Figura 2. Distribuição dos erros de uso por preposição de 5. a a 8. ${ }^{a}$ série

No intuito de corroborar esses indicativos, investigou-se a relação erro versus acerto por preposição, calculando-se o percentual de erro e de acerto sobre a produção total de cada uma delas (ver Figura 3). Nessa análise, confirmou-se que as preposições com maior quantidade tanto absoluta quanto relativa de erros de uso foram $\mathrm{em}$, de e com.

A preposição para, apesar de figurar entre as mais produzidas no corpus, apresentou percentagem de erro de uso significativamente menor que sua percentagem de acerto.

Essa configuração dos erros de uso sugeriu que provavelmente a preposição para seja a de maior grau de facilidade de apropriação. Por outro lado, o com sugeriu ser de alto grau de dificuldade, apresentando o maior índice de erro proporcional ao seu uso. 


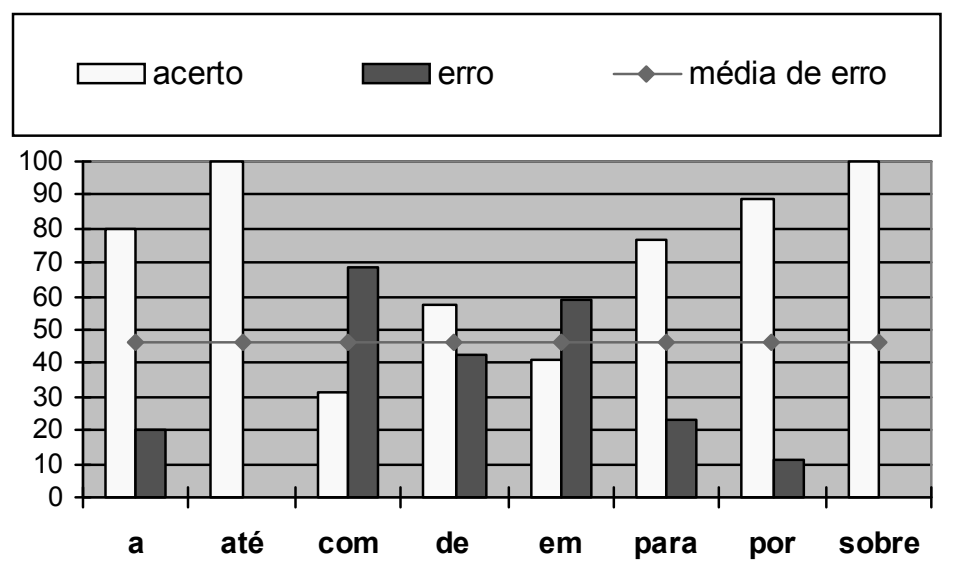

Figura 3. Relação percentual entre acertos e erros no uso das preposições de $5^{\mathrm{a}}$ a $8^{\mathrm{a}}$ série

\subsubsection{Os Erros de Omissão}

Os erros identificados no corpus foram subdivididos por tipo de erro (Tabela 3). Ao analisar-se a tabela abaixo, a primeira e imediata constatação relacionou-se ao fato de que o número total de erros superou o número de usos da preposição, comentado no tópico anterior. A análise efetuada a partir desse dado demonstrou a importância dos erros de omissão nessa investigação.

Tabela 3. Erros por tipo de erro

\begin{tabular}{c|c|c|c|c}
\hline Omissão & $\begin{array}{c}\text { Escolha } \\
\text { Inadequada }\end{array}$ & Ordenação & Adição & Total \\
\hline 297 & 46 & 15 & 47 & $\mathbf{4 0 5}$ \\
\hline
\end{tabular}

Optou-se, no presente estudo, por classificar os erros como de escolha inadequada, ordenação, adição e omissão. Os primeiros três tipos de erro foram contados como erros 
que os aprendizes surdos cometeram ao usar as preposições nos textos que produziram - denominados erros de uso totalizando 108 erros. Os erros de omissão não foram contabilizados como erros de uso, por refletirem exatamente o oposto, ou seja, o não uso da preposição quando requerida pelo contexto.

3.2.4 Os Erros de Omissão da Preposição enquanto Erros Interlingüísticos Versus Erros de Uso da Preposição como Erros Intralingüísticos

Ao calcular o percentual que cada tipo de erro significou no total de erros, a percentagem dos erros de omissão representa $73.4 \%$ (ver Figura 4). O tipo de erro menos freqüente foi o de ordenação com 3.7\% do total de erros, encontrando-se os erros por escolha inadequada e por adição em torno de $11 \%$ de ocorrência cada.

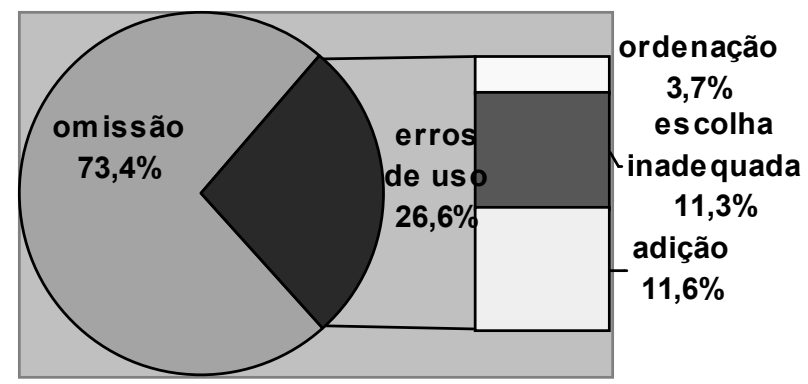

Figura 4. Incidência percentual dos tipos de erro de $5^{\mathrm{a}}$ a $8^{\mathrm{a}}$ série

A partir desses dados, pode-se inferir que a tendência geral dos sujeitos foi a de cometer erros pela não utilização das preposições e não pelo seu uso equivocado. Nesse momento, pode-se argumentar como a LIBRAS gerou 
interferência sobre as preposições na produção escrita dos surdos.

Os erros de omissão podem ser explicados pela interferência da LIBRAS no português, caracterizando um tipo de erro interlingüístico. Os erros de uso podem ser explicados pela formulação de hipóteses sobre o uso das preposições em português apoiadas, primordialmente, no conhecimento que o aprendiz já possuía sobre essa língua alvo. Os erros de uso, portanto, configuraram-se como sendo erros intralingüísticos, ou seja, dificuldades com as quais os aprendizes defrontaram-se dentro da própria língua portuguesa.

Aplicando-se as idéias de Corder $(1967,1971)$ sobre erro aos encontrados na escrita dos aprendizes surdos, compreendeu-se que os erros de uso que os sujeitos cometeram refletiram variadas tentativas de acerto e de aproximação das regras relativas à utilização das preposições na língua portuguesa. Nesse processo de formulação de hipóteses sobre a língua alvo - o português - os alunos cometeram tanto os acertos quanto os erros de uso, analisados anteriormente.

Em contraposição, os erros por omissão atestaram o desconhecimento dos aprendizes acerca do uso das preposições na língua portuguesa. Pelo fato de serem pouco utilizadas na LIBRAS, em geral, as preposições são palavras desconhecidas para os aprendizes surdos. Elas só passam a ser conhecidas a partir do contato do aluno surdo com o português. Como esclarecem Valverde (1990), Coutinho (2000) e Almeida (2000), uma língua espaço-visual prescinde de palavras com a função de conectivos, pois essa conexão é dada pelo uso gramatical do espaço. Por essa razão, os aprendizes surdos de português não perceberam a necessidade dessa classe de palavras em LIBRAS e, 
conseqüentemente, tenderam a omiti-la ao produzirem textos escritos em português. De acordo com Lado (1963), uma estrutura gramatical que apresenta diferenças tão expressivas quanto à forma e ao significado, como as preposições em LIBRAS e em língua portuguesa, constitui área extremamente favorável à interferência. Os dados evidenciaram a predominância dos erros oriundos da interferência da LIBRAS nos casos de preposição identificados na amostra.

3.2.5 Interferência e Fossilização de Erros ao Longo do Processo Educacional

Procurou-se investigar o comportamento das preposições por tipo de erro em cada série, a fim de compreender a evolução da tendência em cometer cada um dos tipos de erro. Os dados ilustrados a seguir (ver Figura 5) demonstraram a tendência à redução dos erros de omissão e ao aumento dos erros de uso, especificamente os erros de adição e de escolha inadequada. Considerouse essa tendência como uma evolução positiva já que se postulou que os erros de uso refletiram a questão de arriscar-se a fim de testar suas hipóteses, passando o aprendiz a lidar com os erros dentro da própria língua alvo, enquanto que os erros de omissão significaram um desconhecimento das estruturas da língua alvo, tendo o aprendiz que recorrer às estruturas da sua L1. 


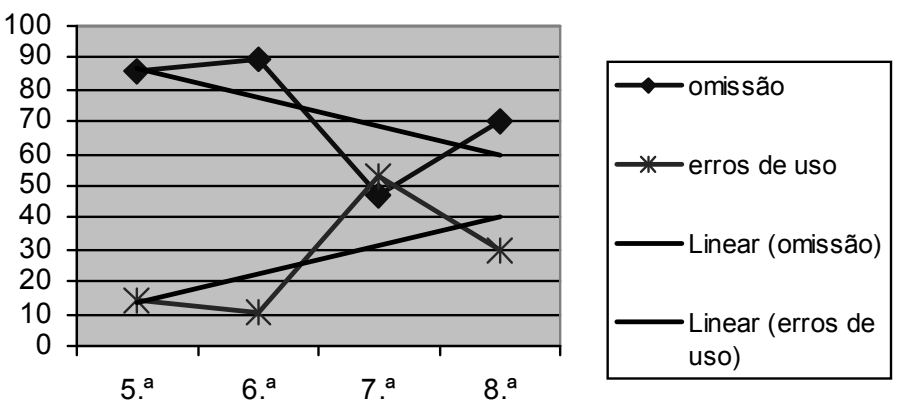

Figura 5. Evolução da freqüência dos tipos de erro por série em percentagem

Nas duas primeiras séries investigadas, os aprendizes apresentaram, na sua maioria, erros motivados pela interferência da LIBRAS na língua portuguesa. Ao longo do processo educacional, os alunos demonstraram ter atingido um maior conhecimento sobre as preposições em textos escritos em português, procurando arriscar-se mais a fim de testar suas hipóteses. Conseqüentemente, o peso da interferência diminuiu como fator causador do erro, aumentando a influência dos erros motivados por fatores intralingüísticos. Todavia, a regressão verificada na 8. ${ }^{a}$ série revelou uma provável dificuldade dos sujeitos na superação de construções marcadas pela interferência, sugerindo a fossilização dos erros de omissão, o que corroborou as observações de Mukattash (1986) e Nakuma (1998) sobre a relação direta entre interferência e fossilização.

A evidência de fossilização dos erros de omissão é corroborada ao analisar os erros sistemáticos. A AE interessase pelos erros que são cometidos pela maioria dos aprendizes, indicados através do índice de propensão, ou seja, pela distribuição mais ou menos ampla do erro pelos diferentes textos. Calculou-se o índice de propensão dividindo-se o número de textos nos quais cada tipo de erro foi identificado 
pelo número total de textos da amostra. Configurou-se a tabela que apresenta os índices de propensão por tipo de erro e por preposição (Tabela 4). Considerou-se como erro sistemático, nesse estudo, os erros que apresentaram índice de propensão igual ou superior a 0.55 , significando que foram identificados pelo menos na metade dos textos mais um.

Confirmou-se, mais uma vez, a importância dos erros de omissão na escrita dos aprendizes surdos, pois todos os erros sistemáticos consistiram em erros de omissão, afetando as preposições de, em, para, com, a, por.

Tabela 4. Índice de propensão

\begin{tabular}{c|c|c|c|c|c}
\hline Preposições & Omissão & $\begin{array}{c}\text { Escolha } \\
\text { Inadequada }\end{array}$ & Ordenação & Adição & $\begin{array}{c}\text { Geral } \\
\text { (por Prepo.) }\end{array}$ \\
\hline a & $\mathbf{0 . 7}$ & 0.0 & 0.0 & 0.05 & $\mathbf{0 . 7 5}$ \\
\hline até & 0.1 & 0.0 & 0.0 & 0.0 & $\mathbf{0 . 1}$ \\
\hline com & $\mathbf{0 . 8 5}$ & 0.15 & 0.2 & 0.15 & $\mathbf{0 . 8 5}$ \\
\hline de & $\mathbf{1 . 0}$ & 0.3 & 0.2 & 0.35 & $\mathbf{1 . 0}$ \\
\hline em & $\mathbf{0 . 9 5}$ & 0.45 & 0.2 & 0.3 & $\mathbf{1 . 0}$ \\
\hline entre & 0.05 & 0.0 & 0.0 & 0.0 & $\mathbf{0 . 0 5}$ \\
\hline para & $\mathbf{0 . 8 5}$ & 0.05 & 0.05 & 0.15 & $\mathbf{0 . 8 5}$ \\
\hline por & $\mathbf{0 . 5 5}$ & 0.0 & 0.0 & 0.05 & $\mathbf{0 . 5 5}$ \\
\hline sob & 0.1 & 0.0 & 0.0 & 0.0 & $\mathbf{0 . 1}$ \\
\hline sobre & 0.35 & 0.0 & 0.0 & 0.0 & $\mathbf{0 . 3 5}$ \\
\hline Geral & $\mathbf{1 . 0}$ & $\mathbf{0 . 6}$ & $\mathbf{0 . 5}$ & $\mathbf{0 . 5}$ & \\
\hline
\end{tabular}

\section{Conclusões}

A língua portuguesa foi tratada, durante toda a pesquisa, como segunda língua do surdo. Para tal, mesclouse a fundamentação teórica desenvolvida para modelos de estudo de L2, especificamente a da Análise Contrastiva e a da Análise de Erros, ao conhecimento acerca das duas línguas envolvidas na educação bilíngüe do surdo, a LIBRAS 
(L1) e o português (L2).

Primeiramente, baseada no contraste entre as preposições da L1 e da L2 do surdo, formulou-se a previsão de que as preposições em geral apresentariam a tendência a ser omitidas na produção escrita do aprendiz surdo de língua portuguesa. Dentro da mesma perspectiva de análise, construiu-se um quadro contrastivo que possibilitou verificar as diferenças e semelhanças entre cada uma das preposições nas duas línguas, estabelecendo-se, enquanto uma segunda previsão, graus de maior ou menor dificuldade para o domínio das preposições do português. No entanto, os resultados encontrados a partir da análise dos erros reais nos textos escritos pelos sujeitos surdos contrariaram essa última previsão. Os resultados apontaram que as preposições mais usadas pelos alunos surdos $(d e, e m)$ estão exatamente entre as que não existem na LIBRAS e que as preposições esperadas como a de maior (para) ou menor (com) grau de dificuldade apresentaram um comportamento oposto ao previsto. Entretanto, a previsão mais geral da AC foi corroborada pelos resultados, comprovando o papel da interferência enquanto fator gerador de erro por analogia, pois a LIBRAS não faz uso de preposições para estabelecer relações entre os termos enunciados, levando o aprendiz a omiti-las no português.

Dizer que as preposições são inexistentes na LIBRAS constitui uma generalização excessivamente ampla, pois se constatou que algumas preposições já foram registradas como fazendo parte dos sinais da LIBRAS. Logo, o que deve ser ressaltado é o seu pouco uso nessa língua devido ao fato de que o próprio uso gramatical do espaço cumpre a função de conectivo entre os sinais. Esse pouco uso pode ser tomado como explicação para as aparentes contradições entre as 
previsões da $\mathrm{AC}$ e os resultados da $\mathrm{AE}$. $\mathrm{O}$ fato de serem pouco usadas na LIBRAS elimina o peso da diferenciação entre as preposições, prevalecendo sua não utilização, o que as coloca todas no mesmo patamar e reforça a tendência geral a sua omissão.

Os erros de omissão foram os predominantes, principalmente nas duas séries iniciais do segundo segmento do ensino fundamental, porém identificou-se outro tipo de erro significativo na escrita dos surdos: o erro de uso da preposição que surgiu a partir da terceira série do referido segmento. Esse tipo de ocorrência traduz as dificuldades que os aprendizes enfrentam na aprendizagem de uma L2 e que são inerentes à própria língua objeto e não à interferência da sua L1.

A inserção desta pesquisa, acerca da produção escrita dos surdos no construto teórico dos estudos de segundas línguas, trouxe algumas sugestões a serem observadas no ensino de português como L2 para o surdo. No intuito de superar os erros de omissão das preposições, um ponto fundamental a ser considerado refere-se à clara diferenciação entre as duas línguas, a LIBRAS e o português, a fim de levar o aluno surdo a compreender a diferença entre essas línguas, assim como sua tendência em omitir as preposições pela interferência da L1. Superada essa dificuldade, sugere-se a exposição intensiva à leitura de textos variados em português como input para a produção das preposições nos textos elaborados pelo aprendiz. Essas tentativas produzem tanto acertos quanto erros de uso. Os erros de uso constituem, na verdade, a formulação de hipóteses baseadas nas regras já aprendidas da própria língua alvo. Essas hipóteses são testadas pelo aprendiz que precisa receber um feedback corretivo, a fim de verificar que hipóteses correspondem ou não às regras da 
língua alvo. Nessa ótica, o erro perde o peso do fracasso, o que implica a promoção de mudanças pedagógicas na forma de abordar o erro na escrita do aluno surdo.

O momento atual demanda pesquisas que focalizem novas formas de ensino-aprendizagem, considerando a aquisição do português pelo surdo como um processo em evolução, que sofre a interferência da L1 na tentativa de atingir a língua alvo. Características lingüísticas singulares emergem no decorrer do processo de aprendizagem de L2 para todos os tipos de aprendizes. Portanto, aproximar os estudos e descrições sobre a linguagem do surdo daqueles que estudam o bilingüismo e o ensino-aprendizagem de L2 abriu interessantes perspectivas na compreensão dos mecanismos de apropriação do português pelo surdo.

\section{Referências Bibliográficas}

ABBAS, A. K. Contrastive analysis: is it a living fóssil? IRAL, v.33, n.3, p.195-215, aug. 1995.

ALMEIDA, E. O. C. de. Leitura e surdez. Rio de Janeiro: Revinter, 2000.

CORDER, S. P. La importancia de los errores del que aprende una lengua segunda. In: LICERAS, J. M. La adquisición de las lenguas extranjeras. Madrid: VISOR, 1992. p.32-40. Tradução do original de CORDER, S. P. The significance of learners erros. IRAL, v.4, p.161-170. 1967.

Dialectos idiosincrásicos y análisis de errores. In: LICERAS, J. M. La adquisición de las lenguas extranjeras. Madrid: VISOR, 1992. p.64-77. Tradução do original de CORDER, S. P. Idiosyncratic dialects and error analysis. IRAL, v.9, n.2, p.147-160. 1971. 
COUTINHO, D. LIBRAS e língua portuguesa: semelhanças e diferenças. João Pessoa: Arpoador, 2000. v. 2.

DULAY, H.; BURT, M. Should we teach children sintax? Language learning, v.24, p.37-53. 1974.

DURÃO, A. B. de A. B. Análisis de errores e interlengua de brasileños aprendices de españoly de españoles aprendices de portugués. Londrina: Ed. UEL, 1999.

A fossilização de erros: o estado da questão. Signum: Estudos da Linguagem, Londrina, n.3, p.47-61, set. 2000.

ELLIS, R. Understand second language acquisition. Oxford: Oxford University Press, 1990.

FANTASIA 2000. Produção: Walt Disney. Manaus: VIDEOLAR, 2000. 1 fita de vídeo (75 min), VHS, son., color.

FERNANDES, S. É possível ser surdo em português? Língua de sinais e escrita: em busca de uma aproximação. In: SKLIAR, C. (Org.). Atualidade da educação bilíngüu para surdos. Porto Alegre: Mediação, 1999. v. 2, p.59-82.

GHADESSY, M. Selection of developmental erros by students with diferent L1 backgrounds. IRAL, v.27, n.1, p.53-63, feb. 1989.

GOLDFELD, M. Surdez. In: Fundamentos em fonoaudiologia: linguagem. Rio de Janeiro: Guanabara Koogan, 1998. p.69-84.

JOKINEN, M. Alguns pontos de vista sobre a educação dos surdos nos países nórdicos. In: SKLIAR, C. (Org.). Atualidade da educação bilíngüe para surdos. Porto Alegre: Mediação, 1999. v.1, p.105-128.

LADO, R. Linguistics across cultures. Toronto, Canada: University of Michigan Press, 1963.

LENNON, P. Error: some problems of definition, indentification, and distinction. Applied Linguistics, Oxford, v.12, n.2, p.180-196. 1991. 
MARCONDES, C. M. C. A.; COSTA, M. P. R. Análise de redações de alunos surdos. In: MORI, N. R. (Org.). Educação especial: olhares e práticas. Londrina: Ed. UEL, 2000. p.177-194.

MUKATTASH, L. Persistence of fossilization. IRAL, v.24, n.3, p.187-203, aug. 1986.

NAKUMA, C. K. A new theorical account of "fossilization": implications for L2 attrition research. IRAL, v.36, n.3, p.247256, aug. 1998.

NICKEL, G. Some controversies in present-day error analysis: 'contrastive' vs. 'non-contrastive' errors. IRAL, v.27, n.4, p.293305, nov. 1989.

PEREIRA, M. C. da C. Discutindo o uso da sintaxe por estudantes surdos. In: CONGRESSO NACIONAL DA ABRALIN, 2, 1999, Resumos... UFSC.

QUADROS, R. M. de. Educação de surdos: a aquisição da linguagem. Porto Alegre: Artes Médicas, 1997.

RABELO, A. S.; SOUZA, J. E. A leitura de obras da literatura infantil, sinalizadas, e o desenvolvimento escrito do surdo. Revista da Sociedade Brasileira de Fonoaudiologia, São Paulo, ano 2, suplemento 1, p.5-9, nov. 1998.

SACKS, O. Vendo vozes: uma jornada pelo mundo dos surdos. Rio de Janeiro: Imago, 1990.

SCHACHTER, J. Second language acquisition and its relationship to universal grammar. Applied Linguistics, Oxford, v.9, n.3, p.219-235. 1988.

SELINKER, L. Interlanguage. IRAL, v.10, n.3, p:209-231. 1972.

SKLIAR, C. La educación de los sordos: una reconstrucción histórica, cognitiva y pedagógica. Mendoza: Ediunc, 1997.

Os estudos surdos em educação: problematizando a normalidade. In: (Org.). A surder: um olhar sobre as diferenças. Porto Alegre: Mediação, 1998. p.7-32. 
TRIADÓ, C. Educación temprana y lenguaje en los niños sordos. In: SKLIAR, C. (Org.). Atualidade da educação bilíngüie para surdos. Porto Alegre: Mediação, 1999. v.1, p.249-258.

TRIVIÑOS, A. N. S. Introdução à pesquisa em ciências sociais: a pesquisa qualitativa em educação. São Paulo: Atlas, 1994.

VALVERDE, F. M. Língua brasileira de sinais - LIBRAS: a visão de um professor de sinais, surdo adulto. In: CICCONE, M. (Org.). Comunicação Total. Rio de Janeiro: Cultura Médica, 1990. p.106107. 